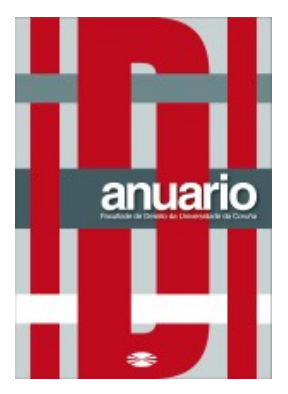

Anuario da Facultade de Dereito da Universidade da Coruña

Vol. 23 (2019), pp. 124-150

ISSNe: 2530-6324 || ISSN: 1138-039X

DOI: https://doi.org/10.17979/afdudc.2019.23.0.6014

\title{
CANDIDATURAS INDEPENDIENTES: ALGUNOS PROBLEMAS PROCESALES EN SU IMPLEMENTACIÓN EN EL PROCESO ELECTORAL 2017-2018 EN MÉXICO
}

\section{INDEPENDENT CANDIDATURES: SOME PROCEDURAL PROBLEMS IN ITS IMPLEMENTATION IN THE 2017-2018 ELECTION PROCESS IN MEXICO}

\author{
MARIO ALBERTO GONZÁLEZ GÓMEZ ${ }^{1}$ \\ VÍCTOR ALEJANDRO WONG MERAZ ${ }^{2}$
}

\begin{abstract}
Resumen: El presente texto tiene el objeto de presentar algunos problemas procesales en la implementación de las candidaturas independientes en México, a partir de la reforma 2014, y particularmente en su primera experiencia en la elección presidencial en el proceso electoral 2017-2018, tomando como marco referencial el caso del candidato Jaime Heliodoro Rodríguez Calderón, para a partir de las sentencias dictadas por el Tribunal Electoral del Poder Judicial de la Federación, identificar problemáticas concretas en aspectos como el derecho de audiencia en la verificación del apoyo ciudadano, las reglas del financiamiento para candidatos independientes, la rigidez en los requisitos y plazos para su cumplimiento, el requisito de dispersión; y por otra parte la asignación de regidurías por el principio de representación proporcional en la elección de ayuntamientos para candidatos independientes. Para una vez expuesta la problemática, presentar alguna propuesta de solución.
\end{abstract}

Palabras clave: Candidaturas independientes, voto pasivo, garantía de audiencia, requisito de dispersión, apoyo ciudadano, financiamiento, representación proporcional.

\footnotetext{
${ }^{1}$ Maestro en Derecho Electoral por el Instituto Estatal Electoral del Estado de México, Especialista en Justicia Electoral por la Escuela Judicial Electoral del Tribunal Electoral del Poder Judicial de la Federación.

${ }^{2}$ Doctor en Derecho Constitucional por la Universidad Complutense de Madrid, profesor investigador de la Universidad Autónoma del Estado de México, profesor de la Escuela Judicial Electoral del Tribunal Electoral del Poder Judicial de la Federación, Miembro del Sistema Nacional de Investigadores Nivel I.
} 


\begin{abstract}
The present text has the purpose to introduce some of the procedural problems in the independent candidatures implementation, in Mexico, after the 2014 amendments, and particularly in their first experience in the presidential elections during the 2017-2018 electoral process, taking the case of candidate Jaime Heliodoro Rodríguez Calderón as a reference framework, starting from the sentences dictated by the Electoral Tribunal of the Federal Judicial Branch, to identify concrete sets of problems in aspects as the right to hearing in citizen support verification, the rules of funding for independent candidates, the rigidity of requisites and terms for their fulfillment, the requirement of dispersion; and moreover, the assignment of regencies by the proportional representation system in the city hall election for independent candidates. In order to, once the set of problems has been presented, propose any possible solutions.
\end{abstract}

Keywords: Independent candidatures, passive voting, hearing guarantee, requirement of dispersion, citizen support, funding, proportional representation.

Sumario: I. INTRODUCCIÓN. II. REQUISITOS PARA CANDIDATURAS INDEPENDIENTES. III. EL CASO DEL CANDIDATO INDEPENDIENTE JAIME HELIODORO RODRÍGUEZ CALDERÓN; GARANTÍA DE AUDIENCIA. IV. REQUISITO DE DISPERSIÓN PARA RECABAR EL APOYO CIUDADANO. V. FINANCIAMIENTO, PREVALENCIA DEL PÚBLICO SOBRE EL PRIVADO. VI. PRINCIPIO DE REPRESENTACIÓN PROPORCIONAL EN LA ELECCIÓN DE AYUNTAMIENTOS. VII. CONCLUSIONES. VIII. COMENTARIO FINAL. IX. FUENTES CONSULTADAS.

\title{
I. INTRODUCCIÓN
}

La constante evolución de los sistemas democráticos ${ }^{3}$ ha implicado el rediseño de las diversas figuras que integran los procesos electorales ${ }^{4}$, incluida la forma de participación política; si bien el tema de las candidaturas independientes, no puede considerarse novedoso en el contexto nacional mexicano, pues la participación de personas ajenas a los partidos políticos, había ya encontrado espacio para su desarrollo en diversas

\footnotetext{
${ }^{3}$ Múgica Herzog, E., SISTEMAS DEMOCRÁTICOS "La democracia no es el silencio, es la claridad con que se exponen los problemas y la existencia de medios para resolverlos"; Instituto Iberoamericano de Altos Estudios Judiciales; España, 2013; consultable en: https://es.slideshare.net/rmferala/sistemas-democraticos$\underline{28074825 .}$.

${ }^{4}$ Proceso electoral. Es el conjunto de actos realizados en fases y que la Constitución y la Ley General de Instituciones y Procedimientos Electorales mandatan a las autoridades electorales, los partidos políticos y los ciudadanos para renovar periódicamente a los integrantes de los Poderes Legislativos y Ejecutivo federal y de las entidades federativas, de los ayuntamientos en los estados de la República y de las alcaldías en la Ciudad de México. Sistema de Información Legislativa; consultable en: http://sil.gobernacion.gob.mx/Glosario/definicionpop.php?ID=193.
} 
entidades federativas, como Tamaulipas, Michoacán, Veracruz, Yucatán, en que ante la petición de ciudadanos que habían solicitado su registro como candidatos a algún cargo de elección popular local, las instancias jurisdiccionales se han pronunciado dando acceso a esta posibilidad de participación política o inclusive en normativa específica que ha regulado esta forma de acceso a los cargos de elección popular local como en Sonora que hasta antes de 2008 establecía esa posibilidad en su legislación ${ }^{5}$.

Sin embargo, la cuestión resulta diversa a nivel federal, pues desde el contexto de la consolidación de la democracia como forma de gobierno, la regla general para el acceso al poder de manera representativa y plural, descansa sobre la base de un sistema de partidos $^{6}$, cuya fortaleza se ha considerado determinante en la búsqueda de esa consolidación democrática.

Parece existir consenso general en que el regreso de las candidaturas independientes puedo haber germinado con al caso Castañeda Gutman ${ }^{7}$, que entre 2005 y 2008, implicaron una serie de actos administrativos y jurisdiccionales, que concluyeron con una determinación de la Corte Interamericana de Derechos Humanos ${ }^{8}$, en que si bien no estableció alguna obligación para el Estado Mexicano de incluir las candidaturas independientes como forma de participación política en su sistema jurídico, la resolución y la exposición del caso, tuvo alcances mediáticos y políticos de magnitud suficiente para poner el tema de manera seria en espacios de análisis jurídico y por supuesto legislativo,

${ }^{5}$ Báez Silva, C. y Tello Mendoza, M.A., El fenómeno de las Candidaturas Independientes en México, Análisis de su Implementación y Primeros Resultados en el Proceso Electoral 2015, Instituto de Investigaciones Jurídicas, Universidad Nacional Autónoma de México, México, 2015, consultable en:

https://drive.google.com/viewerng/viewer?url=https://revistas.juridicas.unam.mx/index.php/derechoelectoral/article/download/10091/12552.

${ }^{6}$ Alarcón Olguín, V. y Reyes del Campillo, J.F.; EL SISTEMA DE PARTIDOS MEXICANO: ¿UNA HISTORIA SIN FIN? Biblioteca Jurídica Virtual del Instituto de Investigaciones Jurídicas de la UNAM, Instituto Nacional electoral, México, 2015; consultable en: https://archivos.juridicas.unam.mx/www/bjv/libros/9/4284/6.pdf.

${ }^{7}$ Los hechos del caso se desarrollan en el marco de un registro de candidaturas presidenciales de México. El 5 de marzo de 2004 Jorge Castañeda presentó al Consejo General del entonces Instituto Federal Electoral una solicitud de inscripción como candidato independiente al cargo de Presidente de los Estados Unidos Mexicanos para las elecciones del 2 de julio de 2006. Alegó que solicitaba su registro "en ejercicio del derecho que le otorga el artículo 35, fracción II de la Constitución”, presentó ciertos documentos y declaró que cumplía los requisitos constitucionales para ejercer dicho cargo electivo. Asimismo, la Dirección Ejecutiva de Prerrogativas y Partidos Políticos, Dirección de Partidos Políticos y Financiamiento del IFE, informó al señor Castañeda Gutman que no era posible atender su petición en los términos solicitados, toda vez que corresponde únicamente a los partidos políticos nacionales el derecho de solicitar el registro de candidatos a cargos de elección popular. Contra dicho pronunciamiento del IFE, Castañeda presentó una demanda de amparo ante el Juzgado Séptimo de Distrito en Materia Administrativa del Distrito Federal, sin embargo, dicho juzgado resolvió rechazar el recurso interpuesto. Asimismo, Castañeda Gutman interpuso un recurso de revisión contra la decisión del Juzgado Séptimo, pero el recurso, atraído por la Suprema Corte de Justicia de la Nación, fue sobreseído. Motivo por el cual acudió a la instancia internacional. Consultable en http://www.corteidh.or.cr/cf/jurisprudencia2/ficha tecnica.cfm?nId_Ficha=298\&lang=es.

${ }^{8}$ Pelayo Möller, C.M ${ }^{a}$ y Vázquez Camacho, S.J., El caso Castañeda ante la Corte Interamericana de Derechos Humanos. Anuario Mexicano de Derecho Internacional, [S.1.], enero de 2009. ISSN 2448-7872. Disponible en: https://revistas.juridicas.unam.mx/index.php/derecho-internacional/article/view/311/546. 
que a la postre concluirían en la inclusión y regulación de las candidaturas independientes en nuestro marco normativo, del que con intención estrictamente contextual, podemos resumir ese tránsito.

De forma que, el 9 de agosto de 2012 se publicó en el Diario Oficial de la Federación (DOF) la reforma al artículo 35, fracción II de la Constitución Política de los Estados Unidos Mexicanos (CPEUM), para permitir la participación de los ciudadanos a través de las candidaturas independientes ${ }^{9}$.

Posteriormente, el 27 de diciembre de 2013 se publica en el DOF la modificación del inciso e) de la fracción IV del artículo 116, eliminando la exclusividad de los partidos políticos para postular candidatos a cargos de elección popular, pero manteniendo el reconocimiento de su derecho a hacerlo ${ }^{10}$, con lo que se armoniza el precepto aludido con el artículo 35, fracción II de la CPEUM.

Finalmente, el 23 de mayo de 2014 se incluyó a nivel legal la figura de candidatura independiente. La Ley General de Instituciones y Procedimientos Electorales ${ }^{11}$, en su libro séptimo, regula las candidaturas independientes para los cargos de Presidente de la República, Diputados y Senadores del Congreso de la Unión, dejando a las legislaturas locales la libertad configurativa ${ }^{12}$ para emitir la normativa aplicable a los candidatos independientes en sus elecciones.

\section{REQUISITOS PARA CANDIDATURAS INDEPENDIENTES}

De manera general, tanto a nivel federal como local, el procedimiento para la participación ciudadana ${ }^{13}$ por la vía de la candidatura independiente, comprende los siguientes pasos: la emisión de la convocatoria correspondiente; que los ciudadanos interesados en registrarse, presenten su manifestación de intención por escrito ante los

\footnotetext{
9 “Artículo 35. Son derechos del ciudadano:

II. Poder ser votado para todos los cargos de elección popular, teniendo las calidades que establezca la ley. El derecho de solicitar el registro de candidatos ante la autoridad electoral corresponde a los partidos políticos así como a los ciudadanos que soliciten su registro de manera independiente y cumplan con los requisitos, condiciones y términos que determine la legislación.

${ }^{10}$ Incorpora el principio de que las constituciones y leyes locales garantizarán que en las elecciones los ciudadanos soliciten su registro como candidatos para poder ser votados en forma independiente a todos los cargos de elección popular.

11 Nueva Ley publicada en el Diario Oficial de la Federación el 23 de mayo de 2014, disponible en: http://www.diputados.gob.mx/LeyesBiblio/pdf/LGIPE_270117.pdf.

12 Juárez Moya, E.F., Justicia constitucional y libertad de configuración legislativa. Problemáticas y perspectivas actuales del ejercicio de la función jurisdiccional en México a cargo de los tribunales de amparo; Revista del Instituto de la Judicatura Federal Instituto de la Judicatura Federal - Consejo de la Judicatura Federal; México, 2015; disponible en: https://revistascolaboracion.juridicas.unam.mx/index.php/judicatura/article/viewFile/31487/28473.

${ }^{13}$ Serrano Rodríguez, A., La participación ciudadana en México. Estud. polít. (Méx.) [online]. 2015, n.34, pp.93-116, disponible en: http://www.scielo.org.mx/scielo.php?script=sci_arttext\&pid=S0185$\underline{16162015000100005}$.
} 
órganos de las autoridades electorales correspondientes; para lo cual, entre otras cuestiones, deben constituir una asociación civil y nombrar a un responsable de la administración de los recursos financieros; por lo que hace al esquema de financiamiento debe ser de origen privado para la etapa de la obtención del apoyo ciudadano, y público y privado para la etapa de las campañas ${ }^{14}$.

Conforme a la libertad configurativa de las legislaturas locales, se reconocen diferencias en los porcentajes respecto de la lista nominal para establecer el número de apoyos ciudadanos que se requieren para obtener el registro por tipo de elección. Los aspirantes que obtengan la calidad de candidato independiente tienen acceso básicamente a las mismas prerrogativas en todos los estados, entre las que destacan el acceso a tiempo en radio y televisión, y financiamiento público. Finalmente, al ser el Instituto Nacional Electoral (INE) el responsable de fiscalizar tanto las elecciones federales como las locales, todas siguen el mismo tipo regulación en materia de fiscalización.

Cabe de manera tangencial, y previa al abordaje del caso en análisis que resultó emblemático en el recién concluido proceso electoral federal, en nuestro tema de candidaturas independientes, mencionar que precisamente la libertad configurativa de las legislaturas locales, determinó reglas que en el desarrollo de los procesos electorales han sido objeto de análisis por las autoridades jurisdiccionales, como lo son los requisitos de dispersión ${ }^{15}$ o la imposibilidad de asignar espacios de representación proporcional para el caso de los ayuntamientos ${ }^{16}$, tratándose de candidatos independientes, que abordaremos más adelante.

$14 \quad$ Acuerdo INE/CG416/2017, $\quad$ consultable en: https://repositoriodocumental.ine.mx/xmlui/bitstream/handle/123456789/93572/CGex201709-08-ap11.pdf? sequence $=1 \&$ is Allowed $=\mathrm{y}$.

${ }^{15}$ SUP-JDC-1163/2017; en este asunto, un ciudadano aspirante a candidato independiente a la gubernatura de Puebla, impugnó ante el Tribunal Local la constitucionalidad de la disposición contenida en el artículo 201 Bis, Fracción I, del Código Electoral del Estado de Puebla, la cual dispone que los aspirantes a candidatos independientes, deberán recabar el apoyo ciudadano equivalente al 3\% de la lista nominal y estar integrada por electores de por lo menos las dos terceras partes de los municipios que componen la entidad. El Tribunal local consideró constitucional este requisito a partir de la aplicación del test de proporcionalidad. Sin embargo, el actor acudió a la instancia federal, cuya determinación establece que 1 exigencia de cumplir con el apoyo ciudadano con electores de por lo menos dos terceras partes de los municipios de la entidad, resulta desproporcionada, pues implica una carga excesiva. Por lo que la Sala Superior resolvió inaplicar la referida porción normativa.

16 Juicio ciudadano SM-JDC-535/2015. En este asunto, la Sala Regional Monterrey analizó si es constitucional excluir a los candidatos independientes del acceso a las regidurías de representación proporcional cuando estos alcanzaron el umbral mínimo para obtener representación en el cabildo, contemplado en la Ley Electoral para el Estado de Nuevo León. En la elección del ayuntamiento de San Pedro Garza García Nuevo León, del año 2015, el triunfo lo obtuvo el PAN con 33,433 votos (51.32\%), el segundo lugar lo tuvo la planilla de candidatos independientes encabezada por Lorenia Canavatti con 11,260 (17.28\%). Aunque la candidatura independiente era la segunda fuerza política más competitiva de esa elección, las autoridades electorales de la entidad le negaron el acceso a cargos de RP, a partir de diversas disposiciones legales del estado de Nuevo León contenidas en los artículos 191, 270, 271 y 272 de la Ley Electoral para el Estado de Nuevo León, que no previene la posibilidad de asignación de regidurías de representación proporcional a planillas integradas por candidatos independientes. Sin embargo, la Sala Monterrey del TEPJF, 


\section{EL CASO DEL CANDIDATO INDEPENDIENTE JAIME HELIODORO RODRÍGUEZ CALDERÓN; GARANTÍA DE AUDIENCIA}

Con este breve panorama, pretendemos sentar las bases mínimas, para entrar a la exposición general de un caso específico que muestra lo que consideramos problemas procesales que fueron presentándose en el desarrollo de la primera experiencia de la figura de candidaturas independientes en la elección a la presidencia de la república en México, posterior a las reformas constitucionales de 2012 y 2013 y su correspondiente reforma legal de 2014.

Así las cosas, en septiembre de 2017, una vez iniciado el proceso electoral federal del 2017-2018, diversos ciudadanos aspirantes a candidato independiente a la presidencia de la república, obtuvieron del Instituto Nacional Electoral, previo el cumplimiento de los requisitos correspondientes, el registro formal como aspirante a candidato independiente a la presidencia de la república, entre ellos Jaime Heliodoro Rodríguez Calderón.

En el desarrollo de las diversas etapas que implica la candidatura independiente, destaca la recolección del apoyo ciudadano, es decir la obtención de un número determinado de firmas de ciudadanos inscritos en la lista nominal, que cuenten con credencial de elector, y que manifiesten su conformidad con apoyar a un candidato independiente; que para el caso de los candidatos a la presidencia de la república es del $1 \%$ de la lista nominal de electores en el país, distribuido en al menos 17 entidades federativas con igual porcentaje en cada una de ellas, en un periodo de 120 días. Porcentaje equivalente a 864,536 ciudadanos ${ }^{17}$.

Una vez concluido el plazo para recabar el apoyo ciudadano, la Dirección Ejecutiva de Prorrogativas y Partidos Políticos (DEPPP) del Instituto Nacional Electoral (INE), emite un dictamen a través del cual determina si el aspirante obtuvo la cantidad de apoyos ciudadanos requeridos.

En el dictamen respectivo, la autoridad administrativa electoral, determinó que Jaime Heliodoro Rodríguez Calderón, no alcanzó el número de apoyos ciudadanos para ser candidato independiente a la presidencia de la república.

concluyó que es inconstitucional excluir a las candidaturas independientes de la asignación de cargos municipales bajo el principio de RP por que se viola el derecho al voto pasivo de los candidatos independientes, porque se vulnera el carácter igualitario del voto y porque excluir a los candidatos independientes de la asignación de RP es contraria al objetivo de la representación proporcional, que es dar representación a las minorías.

17 Acuerdo INE/CG387/2017, denominado ACUERDO DEL CONSEJO GENERAL DEL INSTITUTO NACIONAL ELECTORAL POR EL QUE SE EMITEN LOS LINEAMIENTOS PARA LA VERIFICACIÓN DEL PORCENTAJE DE APOYO CIUDADANO QUE SE REQUIERE PARA EL REGISTRO DE CANDIDATURAS INDEPENDIENTES A CARGOS FEDERALES DE ELECCIÓN POPULAR PARA EL PROCESO ELECTORAL FEDERAL 2017-2018, consultable en: http://www.dof.gob.mx/nota_detalle.php?codigo $=5495706 \&$ fecha=31/08/2017. 
En estas condiciones, Jaime Heliodoro Rodríguez Calderón, en su calidad de aspirante a candidato independiente a la Presidencia de la República, presentó demandas de juicio para la protección de los derechos político-electorales del ciudadano ${ }^{18}$, con el objeto de impugnar los Acuerdos Generales INE/CG269/2018 e INE/CG295/2018 aprobados por el Consejo General del INE, relacionados con el cumplimiento del porcentaje de apoyo ciudadano requerido para el registro de candidaturas independientes a la Presidencia de la República en el proceso electoral 2017-2018, así como la negativa de concederle registro como candidato ${ }^{19}$.

El ciudadano en cuestión formuló diversos agravios tendentes a establecer deficiencias en los mecanismos de revisión de los apoyos ciudadanos, así como inconstitucionalidad de algunas disposiciones de los Lineamientos aprobados por el INE para la revisión. Agravios que fueron estimados infundados por la Sala Superior del Tribunal Electoral del Poder Judicial de la Federación (Sala Superior), al contar el INE con atribuciones para emitir los lineamientos y hacer operativas sus propias determinaciones, así como contar con facultades suficientes para la revisión cuestionada por el actor.

Sin embargo, el actor formuló un agravio, que la Sala Superior estimó razón suficiente para revocar los actos reclamados, consistente en que: la autoridad responsable vulneró su derecho de audiencia, ${ }^{20}$ ya que durante la etapa de revisión preliminar de los apoyos recabados para la obtención del registro correspondiente, el INE, además de haber incurrido en diversos errores; por cuanto a que, en el proceso de verificación de los apoyos ciudadano, se analizaron 387,897 registros y se lograron subsanar un total de 14,426, cantidad que representa un porcentaje significativo, pero no se le permitió revisar la totalidad de los apoyos presentados.

Es decir, el actor señaló que si se le hubiera permitido verificar el universo de apoyos restante habría podido incrementar el número de registros que tendrían que corregirse para ser considerados válidos, lo cual solicitó al INE, pero esta autoridad le negó

\footnotetext{
${ }^{18}$ Ley General del Sistema de Medios de Impugnación en Materia Electoral. Artículo 79.

1. El juicio para la protección de los derechos político-electorales, sólo procederá cuando el ciudadano por sí mismo y en forma individual o a través de sus representantes legales, haga valer presuntas violaciones a sus derechos de votar y ser votado en las elecciones populares, de asociarse individual y libremente para tomar parte en forma pacífica en los asuntos políticos y de afiliarse libre e individualmente a los partidos políticos. En el supuesto previsto en el inciso e) del párrafo 1 del siguiente artículo, la demanda deberá presentarse por conducto de quien ostente la representación legítima de la organización o agrupación política agraviada.

19 SUP-JDC-186/2018 Y SU ACUMULADO SUP-JDC-201/2018, consultables en: https://www.te.gob.mx/Informacion_juridiccional/sesion_publica/ejecutoria/sentencias/SUP-JDC-01862018.pdf.

${ }^{20}$ Silva García, F., Derecho de audiencia: Arts. 14 Constitucional y $8^{\circ}$ de la Convención Americana sobre Derechos Humanos; en Derechos Humanos en la Constitución: Comentarios de Jurisprudencia Constitucional e Interamericana; Instituto de Investigaciones Jurídicas, Universidad Nacional Autónoma de México, Suprema Corte de Justicia de la Nación, México, Fundación Conrad Adenauer, 2013; disponible en: https://archivos.juridicas.unam.mx/www/bjv/libros/8/3568/12.pdf.
} 
tal posibilidad, bajo el argumento de que ya había contado con oportunidad de defensa ${ }^{21}$ y revisado ese universo de firmas.

El agravio fue declarado fundado, toda vez que la Sala Superior consideró que previo a la emisión del Acuerdo por el cual le negaron el registro a la candidatura que aspiraba, la Dirección Ejecutiva de Prerrogativas y Partidos Políticos del INE, debió conceder el derecho de audiencia al actor, respecto de la revisión del total de firmas que fueron descontadas del número de apoyos recabados que ascendió a 2,034,403 no revisadas en ninguna de las comparecencias que tuvo ante la responsable, con motivo de una revisión preliminar de 26 de febrero de 2018, ya que el actor no estuvo en aptitud de verificar materialmente la validez o invalidez del documento básico que acreditó la obtención de tales apoyos.

El Tribunal sostuvo este argumento al considerar que el INE no le señalo al actor las irregularidades específicas en las que incurrió cada apoyo, pues ello se hacía del conocimiento de los aspirantes hasta el momento en que comparecían ante la autoridad electoral administrativa, además, de que existían registros insubsanables a juicio del INE que de ningún modo se le permitieron revisar al actor y ese folio, a su vez, estaba ligado a un acuse del envío de la captura que se notificó al aspirante y a su auxiliar, a través de sus correos electrónicos ${ }^{22}$.

Es decir, la Sala Superior estimó que si bien el actor compareció en diversas ocasiones ante las oficinas del INE, lo hizo sin conocer el procedimiento de calificación de los apoyos y las causas de invalidación de cada uno de ellos, que pudiesen identificarse con un número de folio concreto, lo que en concepto del Tribunal, impidió al actor preparar una defensa completa, ya que sus representantes acudían a solventar dudas sobre la calificación de los apoyos recabados sin contar con algún elemento probatorio con el cual pudiesen objetarla, pues desconocían el motivo por el cual se habían invalidado.

De igual manera, en el caso concreto se advirtió que Jaime Heliodoro Rodríguez Calderón reunió $98.08 \%$ de respaldos válidos respecto del umbral requerido, sin que se le haya permitido revisar todas las supuestas inconsistencias, debido al criterio del INE de que existían irregularidades insubsanables en 849,937 apoyos. Por lo que, únicamente le faltaron $1.92 \%$ para cumplir con el umbral de respaldos ciudadanos requeridos.

\footnotetext{
${ }^{21}$ Cruz Barney, O., El derecho de defensa; Instituto de Investigaciones Jurídicas, Ilustre y Nacional Colegio de Abogados de México, Ilustre Colegio de Abogados de Madrid, México, 2015; disponible en: https://archivos.juridicas.unam.mx/www/bjv/libros/8/3878/7.pdf.

${ }^{22}$ Para el desarrollo de la etapa de recolección del apoyo ciudadano, el INE diseño una aplicación de telefonía móvil, que permitió recabar los apoyos a través de este insumo tecnológico, descrito en el acuerdo INE/CG387/2017, consultable en https://www.ine.mx/wp-content/uploads/2017/09/CGex201708-28-ap12.pdf.
} 
En consecuencia, la Sala Superior consideró que, previo a que el INE negara el registro al actor como aspirante a la Presidencia de la República, debió indicarle de forma detallada que apoyos y por qué motivos, eran rechazados.

De forma que, en la sentencia respectiva, la Sala Superior sostiene que de haber revisado los registros que no fueron verificados durante el procedimiento, el actor hubiese podido alcanzar el umbral exigido para obtener el registro, ya que dentro de las inconsistencias que sí se analizaron, el promovente logró validar 62,730 registros.

Así, el Tribunal afirma que los derechos fundamentales violados originaron un daño inmaterial, particularmente, en el rubro de proyecto de vida; ya que, atendiendo a diversas inconsistencias acontecidas en el procedimiento de verificación de apoyos ciudadanos, el actor no alcanzó su pretensión de ejercer su derecho a ser votado.

De este modo, la Sala Superior consideró que la reparación integral consistía en garantizar que el actor alcanzara su pretensión partiendo del parámetro hipotético de la situación en que se hubiera colocado de no haber acontecido la violación a los derechos humanos, con la omisión de respetar su garantía de audiencia ${ }^{23}$.

En ese orden de ideas, la autoridad jurisdiccional consideró que si bien lo ordinario, hubiera sido revocar el Dictamen y Acuerdo combatidos, para que el INE permitiera al actor revisar las inconsistencias de los apoyos que no fueron revisados por cualquier causa, y hecho lo anterior, determinara lo que en derecho procediera, ello no sería suficiente para reparar el daño causado al actor, por lo que para maximizar el derecho del actor a ser votado, el Tribunal determinó considerar válidos los apoyos recabados por el actor para cumplir con el umbral de apoyo ciudadano requerido para el registro del demandante como candidato independiente a la Presidencia de la República.

De igual forma, el Tribunal estimó, que dado lo avanzado del proceso electoral y la inexistencia de un adecuado ejercicio de la verificación de los apoyos ciudadanos por parte del INE, esta autoridad debería dejar intocados los apoyos ciudadanos que cada uno de los aspirantes hubiera obtenido y estimar totalmente concluido el procedimiento de verificación de apoyos para cualquier candidatura independiente a la Presidencia de la República que hubiese sido o fuere otorgada, incluida la fase de verificación de la duplicidad de respaldos.

En esas condiciones, ordenó al INE otorgar registro a Jaime Heliodoro Rodríguez Calderón como candidato independiente a la Presidencia de la República.

\footnotetext{
${ }^{23}$ Silva García, F., "Derecho de audiencia: Arts. 14 Constitucional y $8^{\circ}$ de la Convención Americana sobre Derechos Humanos", en Derechos Humanos en la Constitución: Comentarios de Jurisprudencia Constitucional e Interamericana, Instituto de Investigaciones Jurídicas, Universidad Nacional Autónoma de México, Suprema Corte de Justicia de la Nación, México, 2013, pág. 1497.
} 
Esta resolución de la Sala Superior, aprobada por mayoría de cuatro de sus integrantes, ha sido ampliamente comentada y cuestionada ${ }^{24}$, por nuestra parte dejaremos de lado cualquier cometario de índole político, y nos limitaremos a emitir algunas consideraciones de lo que estimamos introdujo elementos procesales hasta ese momento poco revisados y que dieron características particulares al caso, pero que debieran ser motivo de atención en los ejercicios electorales futuros, ya que la candidatura independiente se visualiza como una forma de participación política que debe posicionarse como una alternativa que aspire a mayores y mejores alcances entre el abanico de opciones con que contemos los electores.

De tal forma que dedicaremos nuestro primer comentario a lo referido en la sentencia como la vulneración a la garantía de audiencia. Para cuyo efecto iniciaremos señalando que el párrafo segundo del artículo 14 de la Constitución mexicana exige que todo acto privativo sea dictado por tribunales previamente establecidos, en un juicio en el que se observen las formalidades esenciales del procedimiento ${ }^{25}$.

El concepto de "formalidades esenciales del procedimiento" 26 es de carácter complejo e implica cuestiones diversas. Con este término la Constitución hace referencia, en parte, a lo que en otros sistemas jurídicos denominan el "debido proceso" o también el "debido proceso legal". La Corte Interamericana de Derechos Humanos ha señalado que el debido proceso legal se refiere al "conjunto de requisitos que deben observarse en las instancias procesales a efecto que las personas estén en condiciones de defender adecuadamente sus derechos ante cualquier acto del Estado que pueda afectarlos. Es decir, cualquier actuación u omisión de los órganos estatales dentro de un proceso, sea administrativo, sancionatorio o jurisdiccional, debe respetar el "debido proceso legal" 27.

Sobre el tema la jurisprudencia mexicana ha sostenido la siguiente tesis, que es importante en la medida en que descompone los elementos que integran la "fórmula compleja" que contiene el concepto de formalidades esenciales del procedimiento: FORMALIDADES ESENCIALES DEL PROCEDIMIENTO. SON LAS QUE GARANTIZAN UNA ADECUADA Y OPORTUNA DEFENSA PREVIA AL ACTO

\footnotetext{
${ }^{24}$ Rosas Riosegura, X.A., EL TEPJF bajo la lupa en el caso "BRONCO": descripción y resumen de la sentencia; Crónica de las elecciones federales 2018, Instituto de Investigaciones Jurídicas, Universidad Nacional Autónoma de México, México, 2018, disponible en: https://cronicaelectoral.juridicas.unam.mx/posts/post index/353-el-tepjf-bajo-la-lupa-en-el-caso-broncodescripcion-y-resumen-de-la-sentencia.

${ }^{25}$ Artículo 14. ...

Nadie podrá ser privado de la libertad o de sus propiedades, posesiones o derechos, sino mediante juicio seguido ante los tribunales previamente establecidos, en el que se cumplan las formalidades esenciales del procedimiento y conforme a las Leyes expedidas con anterioridad al hecho.

26 Carbonell, M., Formalidades esenciales del Procedimiento; México, 2012; miguelcarbonell.com; consultable

http://www.miguelcarbonell.com/docencia/Formalidades_esenciales_del_procedimiento.shtml.

${ }^{27}$ Se trata de un criterio contenido en varios pronunciamientos de la Corte; por ejemplo, en el "Caso Ivcher Bronstein”, sentencia de 6 de febrero de 2001, párrafo 102 y en Opinión Consultiva 18/03, párrafo 123. Consultable en: http://www.corteidh.or.cr/docs/casos/articulos/Seriec 74 esp.pdf.
} 
PRIVATIVO. La garantía de audiencia establecida por el artículo 14 constitucional consiste en otorgar al gobernado la oportunidad de defensa previamente al acto privativo de la vida, libertad, propiedad, posesiones o derechos, y su debido respeto impone a las autoridades, entre otras obligaciones, la de que en el juicio que se siga "se cumplan las formalidades esenciales del procedimiento". Estas son las que resultan necesarias para garantizar la defensa adecuada antes del acto de privación y que, de manera genérica, se traducen en los siguientes requisitos: 1) La notificación del inicio del procedimiento y sus consecuencias; 2) La oportunidad de ofrecer y desahogar las pruebas en que se finque la defensa; 3) La oportunidad de alegar; y 4) El dictado de una resolución que dirima las cuestiones debatidas. De no respetarse estos requisitos, se dejaría de cumplir con el fin de la garantía de audiencia, que es evitar la indefensión del afectado. Novena Época, Instancia: Pleno, Fuente: Semanario Judicial de la Federación y su Gaceta, Tomo: II, Diciembre de 1995, Tesis: P./J. 47/95, página $133^{28}$.

Como se desprende de esta tesis, las formalidades esenciales del procedimiento se refieren en parte al llamado "derecho de audiencia".

La primera formalidad esencial de todo procedimiento es que la parte afectada sea llamada ante el órgano de autoridad a fin de que pueda defenderse correctamente; el ser llamado no solamente comprende la posibilidad de que el particular sea "avisado" de que se pretende ejecutar un acto privativo en su contra o de que existe un procedimiento que pudiera culminar con la emisión de un acto privativo, sino que, exige poner a su disposición todos los elementos que le permitan tener una información completa, tanto de una demanda interpuesta en su contra (incluyendo los documentos anexos) como en su caso del acto privativo que pretende realizar la autoridad ${ }^{29}$. Además de ser llamado, el particular debe tener la oportunidad de ofrecer pruebas y de que esas pruebas sean desahogadas. En tercer lugar, el particular debe tener el derecho de ofrecer alegatos y de que esos alegatos sean tomados en cuenta por la autoridad; los alegatos, nos indica Héctor Fix Zamudio, son "la exposición oral o escrita de los argumentos de las partes sobre el fundamento de sus respectivas pretensiones una vez agotada la etapa probatoria y con anterioridad al dictado de la sentencia de fondo en las diversas instancias del proceso" 30 .

En cuarto lugar, el derecho de audiencia comprende la obligación del órgano público de dictar una resolución en la que dirima las cuestiones planteadas por las partes ${ }^{31}$.

\footnotetext{
${ }^{28}$ https://sjf.scjn.gob.mx/sjfsist/Paginas/DetalleGeneralV2.aspx?id=200234\&Clase=DetalleTesisBL.

${ }_{29}$ Ovalle Favela, J., Garantías constitucionales del proceso, 2a ed., Oxford University Press, México, 2002, pág. 117.

${ }^{30}$ Fix Zamudio, H., “Alegatos”, en Enciclopedia Jurídica Mexicana, Tomo I, $2^{\text {a }}$ ed., UNAM Porrúa, México 2004, pág. 87.

${ }^{31}$ AUDIENCIA, GARANTIA DE DEBIDO PROCESO. La garantía de audiencia reconocida por el artículo 14 de la Constitución Política de los Estados Unidos Mexicanos, no se contrae a una simple comunicación a la parte afectada para que tenga conocimiento de un acto de autoridad que pueda perjudicarlo, sino que implica el derecho de poder comparecer ante la autoridad a oponerse a los actos que afecten sus propiedades, posesiones o derechos y a exponer las defensas legales que pudiere tener, para lo cual, obviamente, es necesaria la existencia de un juicio en el que se observen, las formalidades esenciales del procedimiento,
} 
El concepto de formalidades esenciales del procedimiento, que como acabamos de ver no está definido en el texto constitucional, sino que ha sido dotado de contenidos concretos por la jurisprudencia, no debe tener un carácter cerrado. Es decir, se puede estar de acuerdo en que, siguiendo la línea jurisprudencial que ya se ha expuesto, las formalidades esenciales del procedimiento se manifiesten en un núcleo duro e irreductible, es decir un contenido mínimo, compuesto por la notificación o emplazamiento, la posibilidad probatoria en sentido amplio, que incluye ofrecimiento, desahogo y valoración de pruebas, el derecho de formular alegatos y la obligación de las autoridades de dictar una resolución dirimiendo la cuestión planteada.

Así, en el caso que nos ocupa, el actor sustenta en sus agravios dieciséis y diecisiete $^{32}$, que "El procedimiento para desahogar el derecho de audiencia fue ineficaz y que la autoridad administrativa no tuvo el tiempo suficiente para la verificación de los apoyos".

Al respecto la Sala Superior estimó fundado el agravio, sustentando su determinación en que contrario a lo resuelto por el Consejo General del INE previo a la emisión del Acuerdo por el cual le negaron el registro a la candidatura que aspiraba, la Dirección Ejecutiva de Prerrogativas y Partidos Políticos del Instituto, sí debió conceder el derecho de audiencia al actor, respecto de la revisión del total de firmas que fueron descontadas del número de apoyos recabados que ascendió a dos millones treinta y cuatro mil cuatrocientos tres y no revisadas en ninguna de las comparecencias que tuvo ante la responsable, con motivo de la revisión preliminar, de veintiséis de febrero de dos mil dieciocho, toda vez que el disconforme no estuvo en aptitud de verificar materialmente la validez o invalidez del documento básico que acreditó la obtención de tales apoyos.

Esta posibilidad abierta de configurar el derecho de audiencia, en el pronunciamiento de la Sala Superior, debía cumplir con los parámetros que permitieran que, al comunicar la situación registral del aspirante, se le debería notificar previamente y de manera individualizada las causas de las supuestas inconsistencias que revestía cada respaldo; además, dichas inconsistencias deberían señalarse con base en los documentos que obrasen en el expediente electrónico de cada apoyo, pues la verificación de estos se

como lo expresa claramente el mencionado precepto constitucional, formalidades que están constituidas, de acuerdo con la teoría del proceso, por el emplazamiento para contestar demanda, un período para ofrecer y rendir pruebas y un plazo para presentar alegatos, a efecto de obtener una sentencia que declare el derecho en controversia, todo lo cual no puede ser satisfecho sino a través del debido proceso que exige el mencionado artículo 14 como garantía individual.

TRIBUNAL COLEGIADO DEL OCTAVO CIRCUITO.

Toca 242/75. Rafael Prieto Torres. 3 de octubre de 1975. Unanimidad de votos. Ponente: Carlos Villegas Vázquez.

Nota: En el Informe de 1975, la tesis aparece bajo el rubro "AUDIENCIA, GARANTIA DE".

${ }^{32}$ Página 13 de la sentencia SUP-JDC-186/2018 Y SU ACUMULADO SUP-JDC-201/2018, consultable en: https://www.te.gob.mx/Informacion_juridiccional/sesion_publica/ejecutoria/sentencias/SUP-JDC-01862018.pdf. 
haría en un momento posterior; de forma que el derecho de audiencia, en el caso específico, debía cumplir con estos parámetros mínimos para que el actor contara con una defensa suficiente que le permitiera afrontar la probable privación de su derecho a alcanzar el umbral de apoyos necesarios para a la postre obtener la calidad de candidato.

Como señalamos líneas antes, esta resolución de la Sala Superior, fue aprobada por mayoría, en el que los votos disidentes consideraron que la negativa de registro de la candidatura independiente de Jaime Heliodoro Rodríguez Calderón debía confirmarse, primordialmente, debido a que las distintas instancias del INE le otorgaron al aspirante diversas oportunidades para que ejerciera de manera oportuna y adecuada, su garantía de audiencia en relación con la verificación de las manifestaciones de apoyo de la ciudadanía. Sosteniendo, además, que de haberse demostrado una verdadera afectación a esta garantía, lo procedente sería únicamente reponer el procedimiento para que se diera la oportunidad a los aspirantes de revisar y rebatir la evaluación de la situación registral de las manifestaciones de apoyo.

Los magistrados disidentes, estimaron que el actor ejerció su garantía de audiencia en diversas oportunidades, ya que se llevaron a cabo un total de trece diligencias con el objeto de que se rectificara la calificación de las manifestaciones de apoyo; además que siempre existió información disponible en el portal Web y recibió información por el propio INE durante las comparecencias, y tan fue suficiente que en algunos casos les fue posible a los representantes del actor, subsanar apoyos, como se advirtió de las diligencias que llevó a cabo el citado instituto, en las que se revisaron un total de 370,805 manifestaciones de apoyo, y se logró rectificar la calificación de 44,268.

Además, consideran adecuado que la autoridad electoral haya negado al actor, en un momento posterior a las oportunidades citadas, la posibilidad de revisar la totalidad de los apoyos que desestimó, y que solamente le haya permitido hacerlo respecto a los apoyos cuya situación registral se modificó a partir de la segunda revisión.

La no revisión de la totalidad de los apoyos de la ciudadanía con inconsistencias es imputable al aspirante, pues fue revisada solo una parte de las manifestaciones y no argumenta en su demanda que en aquel momento haya existido imposibilidad material alguna para realizar una revisión mayor, por lo tanto debería subsistir la invalidez de los apoyos con irregulares no subsanados, pues decidió no ejercer su derecho a la revisión, de manera exhaustiva en una de la fases establecidas en los lineamientos.

Consideran que la vía idónea para la resolución de la controversia, era otorgar al promovente la posibilidad de verificar y subsanar las irregularidades detectadas por la autoridad administrativa, aunque transcurrieran algunos días, pues en su consideración únicamente de esa forma se tendría certeza respecto del cumplimiento de los requisitos para obtener una candidatura independiente. 
Sostienen, además, que la presunción constituye una generalización apresurada, pues a partir de un hecho aislado que es la rectificación del $8 \%$ de los apoyos irregulares detectados, se concluye que dentro del universo restante de apoyos irregulares no convalidados la autoridad calificó incorrectamente 16,653, sin embargo no existe evidencia de ello.

Consideran los autores del voto particular, que no es posible afirmar que la supuesta violación a la garantía de audiencia haya tenido como resultado que el actor no estuviese en la boleta electoral, esto porque el planteamiento en el proyecto de sentencia, implícitamente señala que si el actor hubiese obtenido la garantía de audiencia para la revisión de los apoyos irregulares, habría logrado también subsanar los apoyos ciudadanos irregulares, lo que consideran jurídicamente insostenible, y atenta contra los principios constitucionales de autenticidad, de legalidad y de certeza, pues se sustenta en una especulación.

Este razonamiento expuesto en el voto particular de la minoría de los integrantes de la Sala Superior, nos permite enlazar nuestra siguiente idea respecto de la problemática observada en este proceso electoral en la figura de la candidatura independiente, tomado del caso en estudio.

Pues como hemos observado en varios momentos, la Sala Superior del Tribunal Electoral del Poder Judicial de la Federación, al resolver el expediente SUP-JDC-186/2018 y su acumulado SUP-JDC-201/2018, determinó que previo a que el INE negara el registro al demandante como aspirante a la Presidencia de la República, debió dotar de una dimensión adecuada a las audiencias en las que compareció el actor, debiendo informarle, previo a la comparecencia del actor, a cuáles causas de irregularidad previstas en el artículo $385^{33}$ de la Ley General de Instituciones y Procedimientos Electorales y el numeral 40 de

\footnotetext{
${ }^{33}$ Artículo 385.

1.Una vez que se cumplan los demás requisitos establecidos en esta Ley, la Dirección Ejecutiva del Registro Federal de Electores del Instituto procederá a verificar que se haya reunido el porcentaje de apoyo ciudadano que corresponda según la elección de que se trate, constatando que los ciudadanos aparecen en la lista nominal de electores.

2. Las firmas no se computarán para los efectos del porcentaje requerido cuando se presente alguna de las siguientes circunstancias:

a) Nombres con datos falsos o erróneos;

b) No se acompañen las copias de la credencial para votar vigente;

c) En el caso de candidatos a senador, los ciudadanos no tengan su domicilio en la entidad para la que se está compitiendo;

d) En el caso de candidatos a Diputado Federal, los ciudadanos no tengan su domicilio en el distrito para el que se está postulando;

e) Los ciudadanos hayan sido dados de baja de la lista nominal;

f) En el caso que se haya presentado por una misma persona más de una manifestación a favor de un mismo aspirante, sólo se computará una, y

g) En el caso que una misma persona haya presentado manifestación en favor de más de un aspirante, sólo se computará la primera manifestación presentada.

http://www.diputados.gob.mx/LeyesBiblio/pdf/LGIPE_270117.pdf.
} 
los Lineamientos para la verificación del porcentaje de apoyo ciudadano que se requiere para el registro de candidaturas independientes a cargos federales de elección popular para el Proceso Electoral Federal 2017-2018 ${ }^{34}$, asociaba los folios que respaldaban los apoyos inconsistentes, a fin de que éste preparara sus defensas y estuviera en aptitud, de ser el caso, de ofrecer las pruebas que estimara pertinentes; señalando que el actor debería estar involucrado de manera amplia con la revisión y la determinación de los apoyos sujetos a ella.

De lo cual, advierte que, existe una conclusión objetiva en el sentido de que de haber revisado los registros que no fueron verificados durante el procedimiento, el actor hubiese podido alcanzar el umbral exigido para obtener el registro, puesto que dentro de las inconsistencias que sí se han analizado, el promovente ha logrado validar 62,730 registros.

Con lo cual asume que el margen de $8 \%$ de errores en la clasificación de los apoyos, se debió a la apreciación subjetiva realizada por las personas comisionadas por el INE para tal efecto, lo que conduce a una presunción objetiva y razonable de que pueden existir más apoyos válidos que hayan sido descartados a partir del criterio de los comisionados del INE, máxime, que correspondía a dicho Instituto probar por qué los apoyos previamente validados, posteriormente no fueron tomados en consideración, especialmente, porque era éste quien tenía a su alcance todo el material probatorio; motivo por el cual, la interpretación garantista que debió dar la autoridad ante estos hechos, fue la de privilegiar el derecho de audiencia y no de negarlo, pues ello es contrario al artículo $1^{\circ}$ de la Constitución Política de los Estados Unidos Mexicanos.

Conforme a estas conclusiones, la autoridad jurisdiccional, sustenta su determinación de otorgar registro al actor, en dos figuras jurídicas, en primer término, "la

\footnotetext{
34 40. Para los efectos del porcentaje requerido por la Ley, no se computarán las y los ciudadanos (as) que respalden al candidato (a) independiente, cuando se ubiquen en alguno de los supuestos siguientes:

a) El nombre de la o el ciudadano (a) se presente con datos falsos o erróneos;

b) La imagen de la credencial que se presente no corresponda con la credencial para votar vigente de la o el ciudadano (a);

c) La o el ciudadano (a) no tenga su domicilio en la demarcación territorial para la que se está postulando la o el aspirante; salvo aquellos casos en que se cuente con credencial para votar desde el extranjero para los cargos de Presidente de la República y Senador. Tratándose del cargo de Senador, las credenciales para votar emitidas en el extranjero deberán estar asociadas a la entidad federativa correspondiente.

d) La fotografía de la credencial aparezca en blanco y negro.

e) La o el ciudadano (a) se encuentre dado (a) de baja de la lista nominal;

f) La o el ciudadano (a) no sea localizado (a) en la lista nominal;

g) En el caso que se haya presentado por una misma persona más de una manifestación a favor de un mismo aspirante, sólo se computará una; y

h) En el caso que una misma persona haya presentado manifestación de apoyo en favor de más de un aspirante al mismo cargo, sólo se computará la primera que sea recibida por el Instituto a través de la aplicación informática, siempre y cuando la o el aspirante haya alcanzado el número mínimo de apoyo ciudadano exigido por la Ley y haya cumplido con los requisitos de elegibilidad, así como los establecidos en el artículo 383 de la LGIPE.

http://www.dof.gob.mx/nota_detalle.php?codigo=5495706\&fecha=31/08/2017.
} 
reparación integral" 35 , cuya teoría descansa en la premisa de que toda violación a un derecho humano que haya producido un daño, implica el deber de repararlo adecuadamente, por lo que asume que la reparación debe considerar, en primer lugar, el carácter del daño ocasionado por la autoridad responsable y, en segundo, el hecho de que la restitución se presenta como la medida resarcitoria deseable, para los efectos de la resolución; el análisis de la reparación integral del daño se circunscribe a la restitución de los derechos fundamentales que han sido violentados, tomando en cuenta que aquél es de carácter inmaterial y cuyo impacto descansó en el proyecto de vida del actor, cuya aspiración en ejercicio del derecho político a ser votado, consistió en contender como candidato independiente a la Presidencia de la República. En estas condiciones, la Sala Superior determinó que los derechos fundamentales conculcados (irregularidades en el procedimiento de garantía de audiencia), originaron esencialmente, un daño inmaterial y, particularmente, en el rubro de proyecto de vida; ya que, atendiendo a diversas inconsistencias acontecidas en el procedimiento de verificación de apoyos ciudadanos, el actor no alcanzó su pretensión de ejercer su derecho de voto pasivo. Por lo que, con su determinación, la reparación integral debe garantizar que el actor alcance su pretensión partiendo del parámetro hipotético de la situación en que se hubiera colocado de no haber acontecido la violación al derecho humano de debido proceso.

Así las cosas, dadas las razones originadas en la necesidad de reparar integralmente el derecho político del actor para participar en la contienda a la Presidencia de la República, la resolución maximizó el derecho del quejoso a ser votado en virtud de la confianza legítima ${ }^{36}$ (segunda figura jurídica en que la Sala Superior sustenta su determinación) que originó la responsable en la conducta del actor, la validación del apoyo ciudadano y la apariencia del buen derecho, así como el aspecto temporal en que se ha

\footnotetext{
${ }^{35}$ Calderón Gamboa, J., "La Reparación Integral en la Jurisprudencia de la Corte Interamericana de Derechos Humanos, estándares aplicables al nuevo paradigma mexicano", en Derecho Humanos en la Constitución: Comentarios de Jurisprudencia Constitucional e Interamericana, Instituto de Investigaciones Jurídicas, Universidad Nacional Autónoma de México, Suprema Corte de Justicia de la Nación; México, 2013; pág. 177, disponible en: http://www.corteidh.or.cr/tablas/r33008.pdf.

36 CONFIANZA LEGÍTIMA. CONSTITUYE UNA MANIFESTACIÓN DEL DERECHO A LA SEGURIDAD JURÍDICA, EN SU FACETA DE INTERDICCIÓN DE LA ARBITRARIEDAD. El derecho a la seguridad jurídica, reconocido en los artículos 14 y 16 de la Constitución Política de los Estados Unidos Mexicanos, tutela la prerrogativa del gobernado a no encontrarse jamás en una situación de incertidumbre jurídica $\mathrm{y}$, en consecuencia, en un estado de indefensión; su esencia versa sobre la premisa consistente en "saber a qué atenerse" respecto del contenido de las leyes y de la propia actuación de la autoridad. Sin embargo, no debe entenderse en el sentido de que el orden jurídico ha de señalar de manera especial y precisa un procedimiento para regular cada una de las relaciones que se entablen entre las autoridades y los particulares, sino que debe contener los elementos mínimos para hacer valer el correlativo derecho del gobernado y para que, sobre este aspecto, la autoridad no incurra en arbitrariedades. De lo anterior, puede considerarse la confianza legítima como una manifestación del derecho a la seguridad jurídica, en su faceta de interdicción o prohibición de la arbitrariedad o del exceso, en virtud de la cual, en el caso de que la actuación de los poderes públicos haya creado en una persona interesada confianza en la estabilidad de sus actos, éstos no pueden modificarse de forma imprevisible e intempestiva, salvo el supuesto en que así lo exija el interés público. Al respecto, cabe precisar que, atendiendo a las características de todo Estado democrático, la confianza legítima adquiere diversos matices dependiendo de si se pretende invocar frente a actos administrativos o actos legislativos.
} 
configurado la violación; sustentado en el hecho de que el INE hubiera determinado, que de los 2,034,403 registros captados mediante la aplicación móvil y las cédulas de respaldo, $1,209,607$, se encontraron en Lista Nominal, por lo que aun cuando preliminar, generó en la esfera jurídica del actor una confianza legítima de que el universo de firmas señalado en último lugar, había sido validado, con lo cual, se creó una expectativa razonable a favor del actor, de que había obtenido el porcentaje requerido para que le fuera concedido el registro. Es decir, la Sala Superior estableció una presunción consistente en que con la revisión de los apoyos faltantes, el actor alcanzaría el umbral necesario para obtener el registro a la candidatura pretendida, por lo que los actos procesales que dieron como resultado la negativa de registro del actor como candidato independiente a la Presidencia de la República por estimar que no alcanzaba el umbral necesario exigible, se presentaron de modo tal que, además de no cumplir con las garantías constitucionales y convencionales, evidenciaron un margen de apreciación subjetiva errónea y dudosa suficiente para suponer con alto grado de certeza que el aspirante contaba con el número de apoyos necesarios para tener por satisfecho el requisito. Y concluyó que la consecuencia que debe seguirse es tener por cumplido el requisito consistente en acreditar el apoyo ciudadano en favor del actor ${ }^{37}$.

De los argumentos sustentados por la Sala Superior para su determinación, encontramos como eje rector, irregularidades en el procedimiento de garantía de audiencia, suficientes para estimar vulnerado el debido proceso en perjuicio del actor, quien vio afectado en su perjuicio el principio de "confianza legítima", que dio por resultado la necesidad de aplicar una "reparación integral".

Este argumento implica en sí mismo, un cambio en la línea argumentativa de la Sala Superior, que en asuntos similares, con el mismo precedente de origen respecto que el INE (autoridad responsable) vulneró su derecho de audiencia al determinar la negativa de $\mathrm{su}$ registro como candidatos independientes, sin notificarles previamente, las irregularidades e inconsistencias detectadas durante la verificación de las cédulas de respaldo ciudadano que presentaron para obtener el correspondiente registro, lo que impidió una adecuada defensa; por lo que asumió diversa determinación a la sustentada en previos $\operatorname{asuntos}^{38}$, consistente en revocar el acuerdo correspondiente del Consejo General del Instituto Nacional Electoral, por el cual determinó que no procede el registro del aspirante a candidatos independiente, ordenando la reposición de la garantía de audiencia o su otorgamiento en caso que no hubiese sido concedida. De manera que el INE debía hacer del conocimiento del actor, la causa o supuesto por el que la autoridad responsable consideró que no cumplió, en cada caso, señalando con toda precisión el rubro correspondiente a las exigencias previstas en la normativa aplicable, para que, dentro del plazo definido en la propia sentencia, subsane las inconsistencias u observaciones, y transcurrido el plazo concedido al accionante, el Consejo General del Instituto Nacional Electoral debería emitir,

\footnotetext{
37 Malváez Pardo, G., El principio de protección de la confianza legítima en México; Instituto de Investigaciones Jurídicas, Universidad Nacional Autónoma de México, Universidad Panamericana, México, 2016, disponible en: https://revistas-colaboracion.juridicas.unam.mx/index.php/ars-iuris/article/.../31150.

38 SUP-JDC-1564/2016 Y ACUMULADO SUP-JDC-1568/2016, SUP-JDC-1566/2016; EXPEDIENTE: SUP-JDC-1567/2016.
} 
de manera fundada y motivada, la resolución correspondiente respecto de la solicitud de registro como candidato independiente.

Como se puede advertir, antes de la resolución del SUP-JDC-186/2018, la Sala Superior estimó que ante las inconsistencias en la revisión de los apoyos ciudadanos, lo procedente fue otorgar otro plazo ordenando a la autoridad responsable para dar a conocer al actor la información necesaria y suficiente para una adecuada defensa; en tanto que a partir de esta sentencia, sustentado en la vulneración al principio de "confianza legítima" y al de "reparación integral"; decide otorgar el registro, asumiendo que con la tendencia en la recuperación de apoyos en el proceso de revisión, el actor alcanzaría el umbral requerido para obtener su registro como candidato, lo que implica un cambio en el criterio de la Sala Superior.

De lo hasta ahora expuesto, podemos advertir que el procedimiento que debe seguir el aspirante a candidato independiente tiene una ruta con pasos cuya definición e instrumentación carece de certeza; que si bien no podríamos pretender encontrar soluciones operativas planteando posibles modificaciones al marco constitucional, pues este garantiza la participación ciudadana por esta vía, creemos que estas problemáticas debieran atenderse en los planos legal y reglamentario.

\section{REQUISITO DE DISPERSIÓN PARA RECABAR EL APOYO CIUDADANO}

El caso que hemos empleado para ejemplificar el tortuoso camino que sigue el desarrollo de la candidatura independiente, no solo para el aspirante, sino también para la autoridad administrativa electoral, es solo un marco referencial para presentar algunos problemas explícitos identificables en el caso comentado, pero también otros, que si bien no fueron motivo de controversia en el caso, subyacen en el procedimiento mismo.

Al efecto señalaremos que en la etapa de obtención del apoyo ciudadano, la que implica la acreditación fehaciente del porcentaje requerido en los términos dispuestos por la legislación, que para la candidatura de Presidente de los Estados Unidos Mexicanos, la cédula de respaldo deberá contener cuando menos la firma de una cantidad de ciudadanos equivalente al $1 \%$ de la lista nominal de electores con corte al 31 de agosto del año previo al de la elección y estar integrada por electores de por lo menos diecisiete entidades federativas, que sumen cuando menos el $1 \%$ de ciudadanos que figuren en la lista nominal de electores en cada una de ellas ${ }^{39}$.

Por un lado, si bien lo que se ha denominado como requisito de dispersión, es decir que los apoyos ciudadanos se obtengan en un número determinado de entidades federativas, no fue cuestionado en este caso, forma parte de las exigencias solicitadas por la

\footnotetext{
${ }^{39}$ Artículo 371 numeral 1 de la Ley General de Instituciones y Procedimientos Electorales; consultable en http://www.diputados.gob.mx/LeyesBiblio/pdf/LGIPE_270117.pdf.
} 
ley, cuestionado y combatido en diverso Juicio Ciudadano ${ }^{40}$, y resuelto por la Sala Superior en el sentido de considerar desproporcionado y excesivo el requisito de dispersión, en un asunto controvertido por un aspirante a candidato independiente a la gubernatura de Puebla; en el que al ser cuestionada la constitucionalidad de la disposición contenida en el artículo 201 Bis del Código Electoral de esa entidad, que requería la distribución del apoyo ciudadano en dos terceras partes de los municipios del Estado, la Sala Superior determino que "...lo suficientemente significativo para presentarse como una auténtica opción para obtener mayoría de votos son los respaldos ciudadanos, con independencia de su distribución territorial en la entidad, de manera que carece de justificación exigir que los apoyos ciudadanos provengan de dos terceras partes de los municipios, pues en un absurdo sería tanto como requerir que los votos de mayoría sólo pudieran darle a un candidato partidista el triunfo electoral cuando tuvieran origen en todos esos municipios, sin resultar válido cuando se concentren en algunos municipios o distritos.

En estas condiciones, la Sala Superior a determinado ya la inconstitucionalidad del requisito de dispersión del apoyo ciudadano, por lo que en caso de ser cuestionado el previsto en el artículo 371 numeral 1 de la Ley General de Instituciones y Procedimientos Electorales, debiera, en congruencia ser valorado y resuelto en los mismos términos del asunto ocurrido en el Estado de Puebla que hemos referido.

Por lo que la propuesta en este sentido, es suprimir del citado artículo, la porción normativa que dispone tal exigencia.

Por otro lado, como parte del proceso de verificación de las cédulas de apoyo ciudadano, que en el caso de Jaime Heliodoro Gutiérrez Calderón, hemos observado, la determinación de la Sala Superior fue ordenar al INE otorgara el registro al aspirante; sin embargo, dejando de lado el argumento sustentado por el Tribunal, el origen de la controversia fueron las deficiencias en el proceso de verificación, ya que en estima del Tribunal electoral federal, no se cumplió con la información mínima suficiente por parte del INE, para que el actor desahogara su garantía de audiencia.

Por lo que, en este particular, se trata de una solución o previsión netamente operativa, que debiera quedar subsanada con la especificación en los Lineamientos para la verificación del porcentaje de apoyo ciudadano que se requiere para el registro de candidaturas independientes a cargos federales de elección popular para el Proceso Electoral Federal que en su oportunidad emita el INE al inicio del respectivo proceso electoral federal.

\section{FINANCIAMIENTO, PREVALENCIA DEL PÚBLICO SOBRE EL PRIVADO}

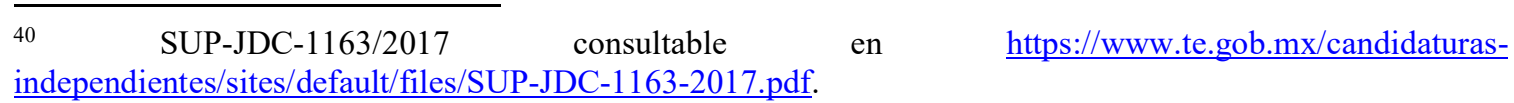


Como hemos señalado, no obstante que en el caso comentado del candidato Rodríguez Calderón, el financiamiento ${ }^{41}$ no fue motivo de disenso jurisdiccional, habrá que recordar que el referido candidato manifestó públicamente su renuncia al financiamiento otorgado por el $\mathrm{INE}^{42}$; lo que nos lleva a revisar brevemente las condiciones de financiamiento a que están sujetos los candidatos independientes de manera general. En principio, recordemos que nuestro orden jurídico ${ }^{43}$ dispone la prevalencia del financiamiento público sobre el privado, y que en el caso de los candidatos independientes, en la etapa de recolección de apoyo ciudadano sólo dispondrán de recursos privados ${ }^{44}$.

Sin embargo, se ha cuestionado que estas disposiciones resultan inequitativas, pues la cantidad a que como candidatos independientes tiene acceso vía financiamiento público, resulta desproporcional contrastada con la que tiene a disposición un candidato de partido. Pero no solo eso, ya que está además el tope de gastos de campaña, problemáticas que en diversos $\operatorname{casos}^{45}$ fueron motivo de estudio y pronunciamiento por parte del Tribunal Electoral del Poder Judicial de la Federación, en los que se determinó que la regla de prevalencia de los recursos públicos sobre los privados, no debe aplicarse a las candidaturas independientes, pues ello resulta inequitativo ${ }^{46}$. Y por otro lado, al ser particulares las condiciones del candidato independiente, y no contar con la infraestructura que respalda a un candidato de partido la regla de nulidad por rebase de tope de gastos superior al $5 \%$ debe flexibilizarse, atendiendo desde luego al caso específico ${ }^{47}$.

\footnotetext{
${ }^{41}$ Bernal Moreno, J.K., El Financiamiento de los Partidos Políticos en el Derecho Comparado. Alternativas para México; Instituto de Investigaciones Jurídicas, Universidad Nacional Autónoma de México, México, 2015, disponible en: https://archivos.juridicas.unam.mx/www/bjv/libros/4/1968/6.pdf.

42 https://www.aztecanoticias.com.mx/el-bronco-renuncia-al-financiamiento-regresa-mas-de-2-mdp-aline $/ 2452733$.

${ }^{43}$ Constitución Política de los Estados Unidos Mexicanos, Artículo 41, fracción II. La ley garantizará que los partidos políticos nacionales cuenten de manera equitativa con elementos para llevar a cabo sus actividades y señalará las reglas a que se sujetará el financiamiento de los propios partidos y sus campañas electorales, debiendo garantizar que los recursos públicos prevalezcan sobre los de origen privado.

${ }^{44}$ Ley General de Instituciones y Procedimientos Electorales, Artículo 374.

1. Los actos tendentes a recabar el apoyo ciudadano se financiarán con recursos privados de origen lícito, en los términos de la legislación aplicable, y estarán sujetos al tope de gastos que determine el Consejo General por el tipo de elección para la que pretenda ser postulado.

2. El Consejo General determinará el tope de gastos equivalente al diez por ciento del establecido para las campañas inmediatas anteriores, según la elección de que se trate.

45 SUP-JDC-222/2018 Y Y Y A https://www.scjn.gob.mx/sites/default/files/sentencias salas tepjf/documento/2018-04/SUP-JDC-2222018.pdf.

${ }^{46}$ Tesis XXI/2015

CANDIDATURAS INDEPENDIENTES. NO LES ES APLICABLE EL PRINCIPIO CONSTITUCIONAL DE PREVALENCIA DEL FINANCIAMIENTO PÚBLICO SOBRE EL PRIVADO, QUE CORRESPONDE A LOS PARTIDOS POLÍTICOS, consultable en: https://www.te.gob.mx/candidaturasindependientes/content/tesis-xxi2015.

${ }^{47}$ SUP-REC-1048/2018, el asunto se refiere a las elecciones de Ayuntamiento del Municipio de Peribán, Michoacán de 2018, en que el triunfo lo obtuvo la planilla encabezada por la candidata independiente Dora Belén Sánchez Orozco: la impugnación fue presentada por el PAN, quien solicitaba la nulidad de la elección derivado del rebase de tope de gasto de campaña en un $7.07 \%$. La ala Regional Toluca determinó que no obstante el rebase, y que la diferencia de votación entre el primero y segundo lugar fue menor al $5 \%$, genera
} 
Otros temas que han sido motivo de controversia y análisis de los tribunales electorales, están vinculados al cumplimiento de requisitos para ser aspirante a candidato independiente, en los que se han flexibilizado los plazos previstos para su cumplimiento, e inclusive se han obviado algunos de ellos al considerarse exigencias desproporcionadas ${ }^{48}$.

\section{PRINCIPIO DE REPRESENTACIÓN PROPORCIONAL EN LA ELECCIÓN DE AYUNTAMIENTOS}

Finalmente, aunque totalmente ajeno al caso comentado, no queremos pasar por alto uno de los aspectos de las candidaturas independientes que nos resulta de particular relevancia y de la entidad suficiente para un análisis particular, pero que al menos de forma breve tocaremos en este punto, el relativo a la representación proporcional ${ }^{49}$ tratándose de $^{2}$ candidatos independientes, y que al menos en el caso de las planillas en la elección de ayuntamientos, tiene prohibición expresa en las legislaturas de algunas entidades.

$\mathrm{Al}$ respecto, la Sala Monterrey ha resuelto ${ }^{50}$ que debe considerarse a los candidatos independientes en la asignación de regidurías por el principio de representación proporcional.

En el juicio ciudadano SM-JDC-535/2015, la Sala Monterrey del Tribunal Electoral del Poder judicial de la Federación, determinó inaplicar en el caso concreto las porciones normativas de los artículos 191, 270, 271 y 27269 de la Ley Electoral del Estado de Nuevo León, en que se analizó si es constitucional excluir a los candidatos independientes del acceso a las regidurías de representación proporcional cuando estos alcanzaron el umbral mínimo para obtener representación en el cabildo. En la elección del ayuntamiento de San Pedro Garza García, Nuevo León, del año 2015, el triunfo lo obtuvo el PAN con 33,433 votos (51.32\%), el segundo lugar lo tuvo la planilla de candidatos independientes encabezada por Lorenia Canavatti con 11,260 (17.28\%). Aunque la candidatura independiente era la segunda fuerza política más competitiva de esa elección, las autoridades electorales de la entidad le negaron el acceso a cargos de Representación

la presunción de determinancia, no resultan razones suficientes para declarar la nulidad de la elección, pues las particularidades del caso, entre ellas la competencia en condiciones de desigualdad en el financiamiento disponible para los candidatos independientes y al que tiene acceso un candidato de partido, además de pertenecer la candidata independiente en grupo desfavorecido.

consultable en: https://www.te.gob.mx/Informacion juridiccional/sesion_publica/ejecutoria/sentencias/SUPREC-1048-2018.pdf.

${ }^{48}$ ST-JDC-271/2017, en el caso, la Sala Toluca del TEPJF, determinó que los plazos a que está sujeto el cumplimiento de los requisitos de aspirantes independientes, deben ampliarse cuando la causa de la demora no sea imputable al Consultable en: https://www.te.gob.mx/salasreg/ejecutoria/sentencias/toluca/ST-JDC-0271-2017.pdf.

49 Solorio Almazán, Héctor; La representación proporcional; Tribunal Electoral del Poder Judicial de la Federación, Temas Selectos de Derecho Electoral, No. 2; México; 2010; disponible en: https://www.te.gob.mx/publicaciones/sites/default/files//archivos libros/02 temas selectos1_0.pdf.

50 SM-JDC-535/2015, consultable en https://www.te.gob.mx/candidaturasindependientes/sites/default/files/SM-JDC-0535-2015.pdf. 
Proporcional, a partir de las citadas disposiciones legales del estado de Nuevo León, que no previene la posibilidad de asignación de regidurías de representación proporcional a planillas integradas por candidatos independientes. Sin embargo, la Sala Monterrey, concluyó que es inconstitucional excluir a las candidaturas independientes de la asignación de cargos municipales bajo el principio de RP por que se viola el derecho al voto pasivo de los candidatos independientes, porque se vulnera el carácter igualitario del voto y porque excluir a los candidatos independientes de la asignación de RP es contraria al objetivo de la representación proporcional, que es dotar de representación a las minorías.

\section{CONCLUSIONES}

En el presente trabajo, hemos expuesto algunas inconsistencias en el constructo normativo que determina la forma en que los candidatos independientes acceden esta forma de participación política, y consecuente con ello, presentamos ahora, las que derivado de los propios criterios jurisdiccionales, se perfilan como eventuales soluciones reglamentarias o legales, según el caso específico. En el primer apartado, nos referimos a la garantía de audiencia como parte del debido proceso legal, en que el Tribunal Electoral del Poder Judicial de la Federación, sostuvo que la autoridad administrativa electoral, al hacer saber al aspirante a candidato independiente, eventuales inconsistencias en sus cédulas de apoyo ciudadano, deberá particularizar cada una de las cédulas cuestionadas, haciendo saber la causa específica de la observación, a efecto que el aspirante esté en posibilidad de preparar una adecuada defensa y subsanar en su caso la inconsistencia respectiva. Situación que consideramos deberá estar específicamente prevista en los lineamientos que al efecto emita el Instituto Nacional Electoral al inicio del proceso electoral federal respectivo, la disposición, actual, prevista en el artículo 45 de los Lineamientos para la Verificación del porcentaje de apoyo ciudadano que se requiere para el Registro de Candidaturas independientes a cargos federales de elección popular para el Proceso Electoral Federal del proceso electoral federal 2017-2018, limita la obligación del INE a hacer saber al aspirante el listado preliminar de los apoyos ciudadanos recabados, así como su situación registral. A partir de ese momento, las y los aspirantes, durante los cinco días subsecuentes, podrán ejercer su garantía de audiencia. Es en este apartado en que consideramos, deberá incluirse la obligación del INE de detallar de manera específica y particular, las inconsistencias que en su caso presentan las cédulas de apoyo sujetas a revisión.

Por otra parte, al referirnos al requisito de dispersión contenido en al artículo 371 de la Ley General de Instituciones y Procedimientos Electorales, el cual dispone que para el caso de la elección a la presidencia de la República, implica la obligación de recabar el 1\% de la lista nominal con corte al 31 de agosto del año previo al de la elección, distribuido en al menos 17 entidades federativas, con sustento en lo resuelto por la TEPJF en el citado asunto de la elección a la gubernatura del estado de Puebla, estimamos pertinente la modificación consistente en la supresión de la porción normativa que describe el requisito de dispersión, que como señalamos, ha sido considerado inconstitucional por la autoridad jurisdiccional electoral. 
Respecto del financiamiento, cuya regla general se encuentra establecida en la fracción II del artículo 41 de la Constitución Federal, consideramos que debe señalarse en el texto constitucional la excepción aplicable a los candidatos independientes, conforme al criterio asumido por la el Tribunal Electoral federal respecto de la no aplicación del criterio de prevalencia de los recursos públicos sobre los privados, dadas las condiciones de inequidad entre candidatos de partido político y los candidatos independientes, por lo que un texto como: "A los candidatos independientes no les es aplicable el principio de prevalencia del financiamiento público sobre el privado, que corresponde a los partidos políticos." O alguno similar, garantizaría en el texto constitucional, condiciones de equidad entre los candidatos de partido y los independientes.

Nos referimos también, a la representación proporcional en las elecciones de ayuntamientos, que si bien es un principio previsto en la fracción VIII del artículo 115 de la Constitución Federal, al disponer que las leyes de los estados introducirán el principio de la representación proporcional en la elección de los ayuntamientos de todos los municipios. Este podría salvaguardar el derecho de las planillas de independientes con alguna adición que previniera garantizar el acceso a las planillas integradas por candidatos independientes.

Finalmente, señalamos que el Tribunal Electoral del Poder Judicial de la Federación se pronunció en diversos fallos, respecto de la necesidad de ampliar los plazos establecidos para el cumplimiento de requisitos para los candidatos independientes, cuando la causa en la demora no les es imputable, situación que de igual forma podría garantizarse en la legislación secundaria.

\section{COMENTARIO FINAL}

No obstante que diversas reglas aplicables a las candidaturas independientes han sido controvertidas ante los tribunales, y estos eliminaron en algunos casos y flexibilizaron en otros, algunas de ellas; no debemos pasar por alto que la candidatura independiente, se encuentra aún en construcción y que su permanencia al lado de los partidos políticos, constituyen un avance significativo en las formas de participación política, y un acicate al propio sistema de partidos que ante el deseable crecimiento de las candidaturas independientes, estará obligado a ofrecer mejores alternativas, pero sobre todo mejores resultados en el ejercicio del poder, a los ciudadanos, que en último caso, son el origen y destino de la consolidación del estado democrático de derecho.

\section{FUENTES CONSULTADAS}

AA.VV., Diccionario Universal en Términos Parlamentarios, coord. Francisco Berlín Valenzuela, Cámara de Diputados, México, 1997.

AA.VV, Los Sistemas de partidos en América Latina 1978-2015 Tomo I, México, América Central y República Dominicana, coord. Flavia Freindberg, UNAM, México, 2015 
Alarcón Olguín, V. y Reyes del Campillo, J.F., EL SISTEMA DE PARTIDOS MEXICANO: ¿UNA HISTORIA SIN FIN? Biblioteca Jurídica Virtual del Instituto de Investigaciones Jurídicas de la UNAM, Instituto Nacional electoral, México, 2015; consultable en: https://archivos.juridicas.unam.mx/www/bjv/libros/9/4284/6.pdf.

Báez Silva, C. y Tello Mendoza, M.A., "El fenómeno de las Candidaturas Independientes en México, Análisis de su Implementación y Primeros Resultados en el Proceso Electoral 2015", en Revista Mexicana de Derecho Electoral, n 7-8, UNAM, México, 2015. ; Instituto de Investigaciones Jurídicas, Universidad Nacional Autónoma de México, México, 2015, consultable

en: https://drive.google.com/viewerng/viewer?url=https://revistas.juridicas.unam.mx/index.php /derecho-electoral/article/download/10091/12552.

Berlín Valenzuela, F., coordinador; Diccionario Universal de Términos Parlamentarios, Cámara de Diputados del H. Congreso de la Unión, México, 1997; consultable en: http://www.diputados.gob.mx/sedia/biblio/virtual/dip/dicc tparla/Dicc Term Parla.pdf.

Bernal Moreno, J.K., El Financiamiento de los Partidos Políticos en el Derecho Comparado. Alternativas para México; Instituto de Investigaciones Jurídicas, Universidad Nacional Autónoma de México, México, 2015, disponible en: https://archivos.juridicas.unam.mx/www/bjv/libros/4/1968/6.pdf.

Calderón Gamboa, J., La Reparación Integral en la Jurisprudencia de la Corte Interamericana de Derechos Humanos, estándares aplicables al nuevo paradigma mexicano; en Derecho Humanos en la Constitución: Comentarios de Jurisprudencia Constitucional e Interamericana; Instituto de Investigaciones Jurídicas, Universidad Nacional Autónoma de México, Suprema Corte de Justicia de la Nación; México, 2013; disponible en: http://www.corteidh.or.cr/tablas/r33008.pdf.

Carbonell, M., Formalidades esenciales del Procedimiento; México, 2012; miguelcarbonell.com; consultable en: http://www.miguelcarbonell.com/docencia/Formalidades_esenciales_del_procedimiento.sht $\underline{\mathrm{ml}}$.

Cruz Barney, O., El derecho de defensa; Instituto de Investigaciones Jurídicas, Ilustre y Nacional Colegio de Abogados de México, Ilustre Colegio de Abogados de Madrid, México, 2015; disponible en: https://archivos.juridicas.unam.mx/www/bjv/libros/8/3878/7.pdf.

Fix Zamudio, H., "Alegatos", Enciclopedia Jurídica Mexicana, 2a ed., México, UNAM, Porrúa, 2004, tomo I.

Juárez Moya, E.F., Justicia constitucional y libertad de configuración legislativa. Problemáticas y perspectivas actuales del ejercicio de la función jurisdiccional en México a 
cargo de los tribunales de amparo; Revista del Instituto de la Judicatura Federal Instituto de la Judicatura Federal - Consejo de la Judicatura Federal; México, 2015; disponible en: https://revistas-

colaboracion.juridicas.unam.mx/index.php/judicatura/article/viewFile/31487/28473.

Malváez Pardo, G., El principio de protección de la confianza legítima en México; Instituto de Investigaciones Jurídicas, Universidad Nacional Autónoma de México, Universidad Panamericana, México, 2016, disponible en: https://revistascolaboracion.juridicas.unam.mx/index.php/ars-iuris/article/.../31150.

Múgica Herzog, E., SISTEMAS DEMOCRÁTICOS "La democracia no es el silencio, es la claridad con que se exponen los problemas y la existencia de medios para resolverlos"; Instituto Iberoamericano de Altos Estudios Judiciales; España, 2013; consultable en: https://es.slideshare.net/rmferala/sistemas-democraticos-28074825.

Ovalle Favela, J., Garantías constitucionales del proceso, $2^{\mathrm{a}}$ edición, México, Oxford University Press, 2002, Reforma Judicial, Revista Mexicana de Justicia, Instituto de Investigaciones Jurídicas, Universidad Nacional Autónoma de México, disponible en: https://revistas.juridicas.unam.mx/index.php/reforma-judicial/article/view/8577/10608.

Pelayo Möller, C.M ${ }^{\mathrm{a}}$. y Vázquez Camacho, S.J., El caso Castañeda ante la Corte Interamericana de Derechos Humanos. Anuario Mexicano de Derecho Internacional, [S.1.], enero de 2009. ISSN 2448-7872. Disponible en: https://revistas.juridicas.unam.mx/index.php/derecho-internacional/article/view/311/546.

Rosas Riosegura, X.A., EL TEPJF bajo la lupa en el caso "BRONCO": descripción y resumen de la sentencia; Crónica de las elecciones federales 2018, Instituto de Investigaciones Jurídicas, Universidad Nacional Autónoma de México, México, 2018, disponible en: https://cronicaelectoral.juridicas.unam.mx/posts/post index/353-el-tepjfbajo-la-lupa-en-el-caso-bronco-descripcion-y-resumen-de-la-sentencia.

Serrano Rodríguez, A., La participación ciudadana en México. Estud. polít. (Méx.) [online]. 2015, n.34, pp.93-116, disponible en: http://www.scielo.org.mx/scielo.php?script=sci arttext\&pid=S0185-16162015000100005.

Silva García, F.; Derecho de audiencia: Arts. 14 Constitucional y $8^{\circ}$ de la Convención Americana sobre Derechos Humanos; en Derechos Humanos en la Constitución: Comentarios de Jurisprudencia Constitucional e Interamericana; Instituto de Investigaciones Jurídicas, Universidad Nacional Autónoma de México, Suprema Corte de Justicia de la Nación, México, Fundación Conrad Adenauer, 2013; disponible en: https://archivos.juridicas.unam.mx/www/bjv/libros/8/3568/12.pdf.

Solorio Almazán, H., La representación proporcional; Tribunal Electoral del Poder Judicial de la Federación, Temas Selectos de Derecho Electoral, No. 2; México; 2010; disponible 
en:

https://www.te.gob.mx/publicaciones/sites/default/files//archivos_libros/02 temas_selectos 1_0.pdf.

Corte Interamericana de Derechos Humanos, Ficha Técnica: Castañeda Gutman Vs. México, consultable en: http://www.corteidh.or.cr/cf/jurisprudencia2/ficha_tecnica.cfm?nId_Ficha=298\&lang=es.

Corte Interamericana de Derechos Humanos, Caso Ivcher Bronstein Vs. Perú Sentencia de 6 de febrero de 2001 (Reparaciones y Costas); consultable en: http://www.corteidh.or.cr/docs/casos/articulos/Seriec 74 esp.pdf.

Instituto Nacional Electoral, Acuerdo INE/CG416/2017, denominado ACUERDO DEL CONSEJO GENERAL DEL INSTITUTO NACIONAL ELECTORAL POR EL QUE SE EMITELA CONVOCATORIA PARA EL REGISTRO DE CANDIDATURASINDEPENDIENTES ALA PRESIDENCIA DE LA REPÚBLICA, SENADURÍAS O DIPUTACIONES FEDERALES POR EL PRINCIPIO DE MAYORÍA RELATIVAPARA EL PROCESO ELECTORAL FEDERAL 2017-2018; consultable

https://repositoriodocumental.ine.mx/xmlui/bitstream/handle/123456789/93572/CGex2017 09-08-ap-11.pdf? sequence=1\&isAllowed=y.

Instituto Nacional Electoral, Acuerdo INE/CG387/2017, denominado ACUERDO DEL CONSEJO GENERAL DEL INSTITUTO NACIONAL ELECTORAL POR EL QUE SE EMITEN LOS LINEAMIENTOS PARA LA VERIFICACIÓN DEL PORCENTAJE DE APOYO CIUDADANO QUE SE REQUIERE PARA EL REGISTRO DE CANDIDATURAS INDEPENDIENTES A CARGOS FEDERALES DE ELECCIÓN POPULAR PARA EL PROCESO ELECTORAL FEDERAL 2017-2018, consultable en: http://www.dof.gob.mx/nota_detalle.php? codigo $=5495706 \&$ fecha $=31 / 08 / 2017$.

Sala Superior del Tribunal Electoral del Poder Judicial de la Federación, expediente SUPJDC-1163/2017 consultable en https://www.te.gob.mx/candidaturasindependientes/sites/default/files/SUP-JDC-1163-2017.pdf.

Sala Superior del Tribunal Electoral del Poder Judicial de la Federación, expediente SUPJDC-186/2018 Y SU ACUMULADO SUP-JDC-201/2018, consultables en: https://www.te.gob.mx/Informacion_juridiccional/sesion_publica/ejecutoria/sentencias/SU P-JDC-0186-2018.pdf.

Sala Superior del Tribunal Electoral del Poder Judicial de la Federación, expediente SUPJDC-222/2018 Y ACUMULADOS, consultable https://www.scjn.gob.mx/sites/default/files/sentencias_salas tepjf/documento/201804/SUP-JDC-222-2018.pdf. 
Sala Superior del Tribunal Electoral del Poder Judicial de la Federación, expediente SUPREC-1048/2018, https://www.te.gob.mx/Informacion_juridiccional/sesion_publica/ejecutoria/sentencias/SU P-REC-1048-2018.pdf.

Sala Superior del Tribunal Electoral del Poder Judicial de la Federación, Tesis XXI/2015. CANDIDATURAS INDEPENDIENTES. NO LES ES APLICABLE EL PRINCIPIO CONSTITUCIONAL DE PREVALENCIA DEL FINANCIAMIENTO PÚBLICO SOBRE EL PRIVADO, QUE CORRESPONDE A LOS PARTIDOS POLÍTICOS, consultable en: https://www.te.gob.mx/candidaturas-independientes/content/tesis-xxi2015.

Sala Monterrey del Tribunal Electoral del Poder Judicial de la Federación, expediente SMJDC-535/2015, consultable en https://www.te.gob.mx/candidaturasindependientes/sites/default/files/SM-JDC-0535-2015.pdf.

Sala Toluca del Tribunal Electoral del Poder Judicial de la Federación, expediente ST-JDC271/2017, en el caso, la Sala Toluca del TEPJF, determinó que los plazos a que está sujeto el cumplimiento de los requisitos de aspirantes independientes, deben ampliarse cuando la causa de la demora no sea imputable al aspirante. Consultable en: https://www.te.gob.mx/salasreg/ejecutoria/sentencias/toluca/ST-JDC-0271-2017.pdf.

Azteca Noticias, nota periodística, consultable en: https://www.aztecanoticias.com.mx/elbronco-renuncia-al-financiamiento-regresa-mas-de-2-mdp-al-ine/2452733.

Constitución Política de los Estados Unidos Mexicanos, http://www.diputados.gob.mx/LeyesBiblio/ref/cpeum.htm.

Ley General de Instituciones y Procedimientos Electorales, http://www.diputados.gob.mx/LeyesBiblio/pdf/LGIPE_270117.pdf.

Ley General del Sistema de Medios de Impugnación en Materia Electoral, http://www.diputados.gob.mx/LeyesBiblio/pdf/149_190118.pdf.

Lineamientos para la verificación del porcentaje de apoyo ciudadano que se requiere para el registro de candidaturas independientes a cargos federales de elección popular para el Proceso Electoral Federal 2017-2018 (Instituto Nacional Electoral) https://www.ine.mx/wp-content/uploads/2017/09/ANEXO-1-CG387-17.pdf. 